\title{
Metastatic Thyroid Gland Papillary Carcinoma
}

National Cancer Institute

\section{Source}

National Cancer Institute. Metastatic Thyroid Gland Papillary Carcinoma. NCI Thesaurus.

Code C156100.

A papillary carcinoma that arises from the thyroid gland and has metastasized to another anatomic site. 